\title{
Understanding through therapeutic writing
}

\author{
Still Here: A Post-Cocktail AIDS Anthology \\ Collected and edited by Allan Peterkin \\ and Julie Hann \\ Life Rattle Press; 2008 \\ 327 pp \$25.00 ISBN 978-1-897161-55-5
}

"Psychologically, I see my personal facts the way they are, not as how I would like to see them. Admitting the truth has become a little easier." - From the book under review.

$\mathrm{W}$ hen we experience change, uncertainty or loss, the most useful response, although not always the most natural, is to try to make sense of what is happening. To do this, some turn to psychotherapy. Others write. At the Clinic for HIV-Related Concerns at Mount Sinai Hospital in Toronto, Ontario, people living with HIV may choose to do both at once.

Still Here: A Post-Cocktail AIDS Anthology is a collection that arose out of the Therapeutic Writing Group facilitated by psychiatrist Allan Peterkin and occupational therapist Julie Hann. The essays, collected over 8 years, reflect the experiences of people living with HIV since the advent of the antiretroviral medication "cocktails" that have prolonged the lives of many patients.

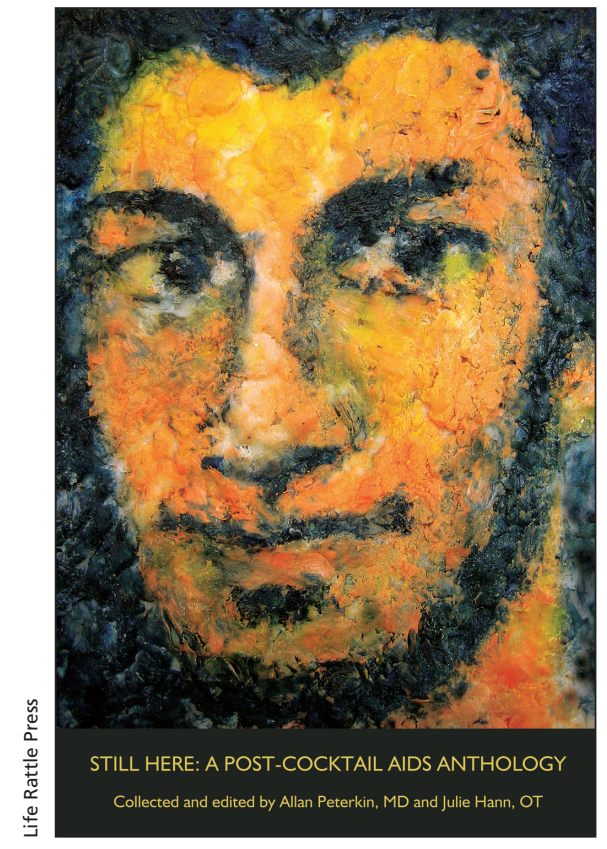

The potential value of this approach can be appreciated from participant feedback. One commented that he "had to make something rational, organized, confront things without rambling." Many of the benefits identified by participants would be difficult to provide using other therapeutic modalities. For example, one person reported he was "less likely to forget my stories versus forgetting what I said in therapy the week before." Another valued the "pos-

\section{I value the "possibility to reread then reanalyze my old thoughts." - Contributor to Still Here.}

In the group, participants are encouraged to create a "competent" narrative that is comprehensible to other members when the work is read aloud. The pieces are meant to incorporate feelings as well as facts, and the authors' own insights are an important part of the finished essay. sibility to reread then reanalyze my old thoughts." "Now able to share my stories with my family so they can understand me better," was another comment.

The essays in the anthology are grouped under 5 themes: change, hope, severance, treatment and loss. There are often strong emotions expressed, includ- ing grief, anger and fear, although some have a lighter and even humourous touch. The writers are articulate in describing their experiences, and it is obvious that time and thought has gone into polishing the works before publication.

In a brief appendix at the end of the anthology, the editors explain the process for forming an expressive writing group. Before setting up the group, Peterkin and Haan consulted with Guy Allen $\mathrm{PhD}$, a professor of writing at the University of Toronto. They also reviewed the literature on narrative and therapeutic writing, including the writings of James Pennebaker and Michael White. The anthology features instructions on how to start and run a group, ranging from pointers on selecting patients to how to improve the quality of the compositions themselves. Not only is this an interesting topic, the notion of setting up an expressive writing group may be attractive to many health care professionals. While the authors do provide a list of references, it still might have been worthwhile to expand this section.

As a psychiatrist who does not have any HIV-positive patients at the present time, I was engaged and challenged by this book. Reading it caused me to reflect on the experiences that are unique to patients with AIDS as well as those that are common to other medical and psychiatric illnesses. This anthology would be of particular interest to patients, family members and those who work with people with AIDS, and could be useful for teaching medical students or other learners.

Ultimately, it is the authors of these stories who will find the greatest value in them, and in the process of their creation. As one writer says, "I believe in the strength, wisdom and effect of my stories. Ergo, I believe in myself."

\section{Lara Hazelton MD}

Psychiatrist

Halifax, NS 